\title{
ESTABILIDADE OPERACIONAL DA LIPASE DE Mucor circinelloides IMOBILIZADA EM POLIURETANO NA ETANÓLISE DO ÓLEO DE BABAÇU EM REATOR DE LEITO FIXO
}

\author{
G. S. S. ANDRADE ${ }^{1}$, A. K. F. CARVALHO ${ }^{2}$ e H. F. DE CASTRO ${ }^{2}$ \\ ${ }^{1}$ Universidade Federal de Alfenas, Instituto de Ciência e Tecnologia \\ ${ }^{2}$ Universidade de São Paulo, Escola de Engenharia de Lorena \\ E-mail para contato: grazielle.andrade@unifal-mg.edu.br
}

\begin{abstract}
RESUMO - A estabilidade operacional de células íntegras de Mucor circinelloides imobilizadas em espuma de poliuretano foi determinada na etanólise contínua do óleo de babaçu em meio contendo terc-butanol como solvente. As etanólises foram conduzidas em reator de leito fixo (volume útil de $310 \mathrm{~cm}^{3}$ ) empacotado com $27 \mathrm{~g}$ do biocatalisador, operando a $35^{\circ} \mathrm{C}$ e tempo espacial de $4,8 \mathrm{~h}$. O desempenho do sistema foi avaliado utilizando células imobilizadas não tratadas (controle) e tratadas com solução de glutaraldeído $(0,1 \%)$ e Aliquat® $336(0,1 \%)$. A comparação do desempenho do reator indicou que o biocatalisador tratado com glutaraldeído permitiu manter estável a operação do sistema por 15 dias sem redução relevante da concentração dos ésteres de etila $(55,2 \pm$ $4,0 \mathrm{~m} / \mathrm{m} \%$ ), correspondendo a rendimentos médios de $67,8 \pm 6,5 \%$, revelando um tempo de meia-vida do biocatalisador de 42,8 dias.
\end{abstract}

\section{INTRODUÇÃO}

O uso de processos enzimáticos em substituição à catálise química tradicional desponta como uma alternativa adequada para que sejam desenvolvidos processos eficientes de obtenção de produtos de interesse não agressivos do ponto de vista ecológico (Abbaszaadeh et al., 2012). Entretanto, muitas aplicações industriais desses biocatalisadores são ainda limitadas pelo seu alto custo de produção e baixa produtividade, pois sendo em sua maioria enzimas extracelulares requer etapas posteriores de separação purificação e imobilização em suporte, por processos complexos para uso prático (RoblesMedina et al., 2009).

Como forma de reduzir estes custos, diversos estudos estão sendo direcionados na utilização de células íntegras de fungos filamentosos como biocatalisadores. Grande parte desses estudos reporta a utilização de células imobilizadas in situ em suporte adequado. Esta estratégia tem apresentado resultados promissores empregando diferentes fungos produtores de lipase intracelular para mediar reações de hidrólise, esterificação e principalmente transesterificação de óleos vegetais, visando à obtenção do biodiesel (Fukuda et al., 2009).

Em trabalhos anteriormente desenvolvidos células do fungo Mucor circinelloides imobilizadas em poliuretano apresentaram elevado desempenho como biocatalisador na etanólise de óleo de 


\section{9 a 22 de outubro de 2014 \\ Florianópolis/SC}

babaçu (Andrade et al., 2012). Utilizando os dados gerados em reatores agitados operados em regime de batelada, estudos foram conduzidos em regime de fluxo contínuo comparando a estabilidade operacional do sistema imobilizado, mediante a utilização de agentes de ativação (glutaraldeído) e líquido iônico (sal de amônio quaternário de cloreto de amônio-Aliquat ${ }^{\circledR}$ 336), uma fonte versátil e acessível para uma família inteiramente nova de líquidos iônicos hidrofóbicos. Aliquat® 336 tem sido usado com sucesso em diversos segmentos, incluindo como agente modificador da permeabilidade em membranas poliméricas, principalmente latex, PVC e poliuretano ou como aditivo na bioencapsulação de lipase em matrizes sol-gel (Souza et al., 2012).

\section{MATERIAIS E MÉTODOS}

\subsection{Materiais}

Os experimentos foram realizados empregando a linhagem do fungo Mucor circinelloides URM 4182 adquirida da coleção de culturas da Micoteca URM (CCB/UFPe). Como suporte de imobilização foi utilizado espumas de poliuretano comercial (Scotch-Brite ${ }^{\mathrm{MR}}$ ) cortadas em cubos de 6 $\mathrm{mm}$, com densidade aparente de $0,02 \pm 0,01 \mathrm{~g} / \mathrm{cm}^{3}$ e diâmetro médio de poros de $0,36 \pm 0,14 \mathrm{~mm}$. $\mathrm{O}$ fungo foi cultivado em meio de cultura líquido composto por óleo de oliva (comercial) 30g/L, peptona (Himedia) 70g/L, $\mathrm{NaNO}_{3}$ (Vetec) $1 \mathrm{~g} / \mathrm{L}, \mathrm{KH}_{2} \mathrm{PO}_{4}$ (Synth) $1 \mathrm{~g} / \mathrm{L}$ e $\mathrm{MgSO}_{4} .7 \mathrm{H}_{2} \mathrm{O}$ (Vetec) $0,5 \mathrm{~g} / \mathrm{L}$, previamente autoclavados $\left(121^{\circ} \mathrm{C} / 15 \mathrm{~min}\right)$. Como materiais de partida foram utilizados óleo de babaçu refinado (Pulcra Chemicals) e etanol anidro (Cromoline). Terc-butanol (Cromoline) foi utilizado como solvente. As células imobilizadas foram tratadas com glutaraldeído $25 \%$ (Cromoline) e cloreto de metiltrioctilamônio (Aliquat 336®, Sigma-Aldrich).

\subsection{Metodologia experimental}

Em Erlenmeyer de $250 \mathrm{~mL}$, contendo $100 \mathrm{~mL}$ do meio de cultura, foram inoculados assepticamente $1 \times 10^{6}$ esporos/mL do fungo, juntamente com 100 cubos de poliuretano. Os frascos foram incubados por $72 \mathrm{~h}$ a $30^{\circ} \mathrm{C}$ sob agitação orbital $(170 \mathrm{rpm})$. A biomassa imobilizada foi separada do meio de cultura por filtração a vácuo, lavada com água e tratada com soluções de glutaraldeído ou Aliquat $336(0,1 \%$ em tampão fosfato $\mathrm{pH} 7,0)$ por $1 \mathrm{~h}$ a $25^{\circ} \mathrm{C}$. As células foram recuperadas por filtração a vácuo, lavadas com água e acetona e secas em bomba de alto vácuo. As reações de transesterificação em fluxo contínuo foram realizadas em reator de leito fixo, conforme Figura 1 (diâmetro interno $=45 \mathrm{~mm}$, comprimento $=190 \mathrm{~mm}$ e volume total $=310 \mathrm{~cm}^{3}$ ), operando numa vazão de $0,13 \mathrm{~mL} / \mathrm{min}$, por 15 dias. A mistura reacional composta por óleo de babaçu e etanol (razão molar 1:6 óleo/etanol) e terc-butanol como solvente foi mantida a $35^{\circ} \mathrm{C}$. A coluna foi empacotada com $27 \mathrm{~g}$ de células imobilizadas (densidade média de $0,102 \pm 0,001 \mathrm{~g} / \mathrm{cm}^{3}$ ) correspondendo a um volume útil de $270 \mathrm{~cm}^{3}$. O monitoramento do processo foi efetuado pela quantificação dos ésteres de etila formados por cromatografia e da viscosidade dos ésteres purificados. 


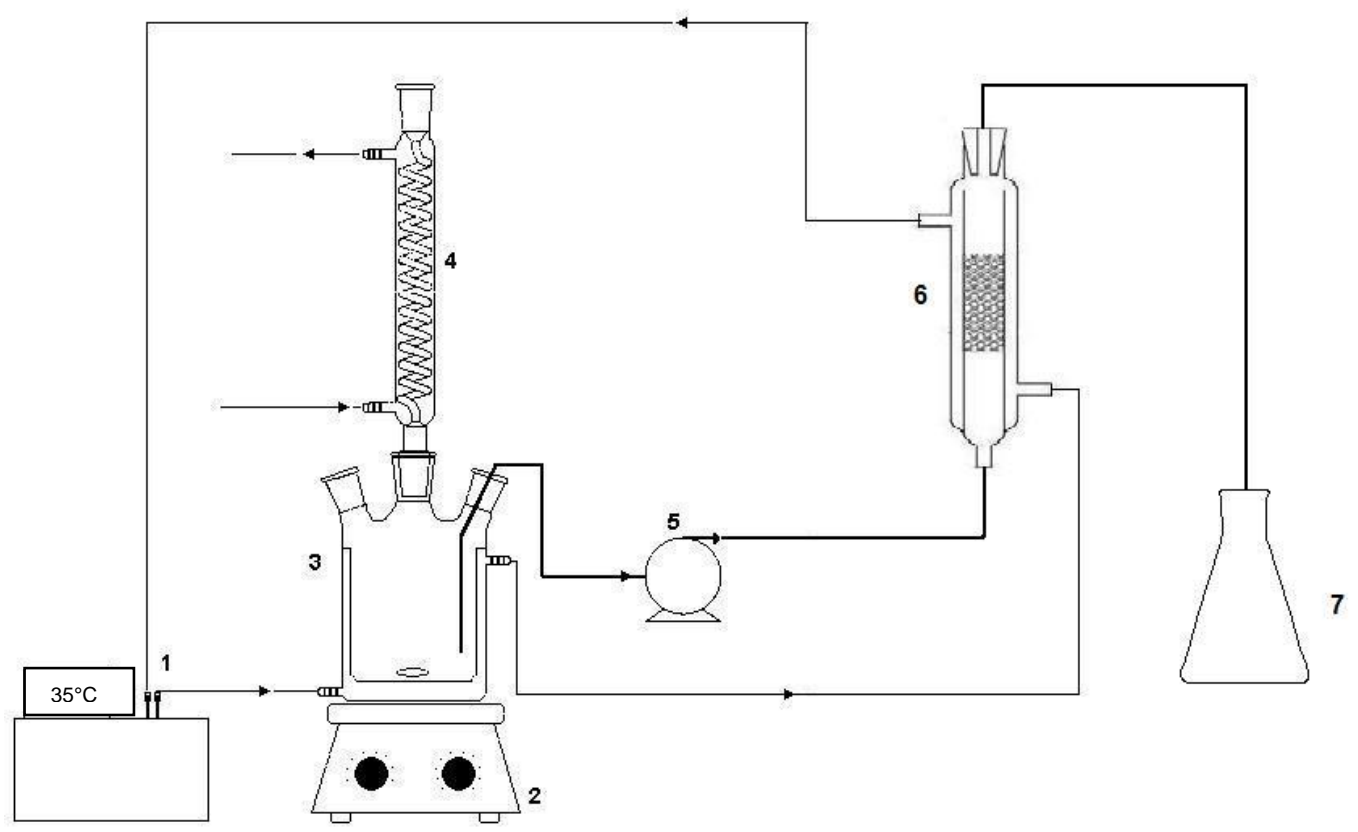

Figura 1. Esquema simplificado do reator de leito fixo. 1- Banho termostático, 2- Agitador magnético, 3- Tanque de alimentação, 4- Condensador de refluxo, 5- Bomba peristáltica, 6- Reator tipo leito fixo, 7- Saída de produto.

\subsection{Metodologia analítica}

A atividade enzimática das células imobilizadas foi determinada pelo método modificado de hidrólise do azeite de oliva (Andrade et al., 2012). A umidade das células íntegras imobilizadas foi determinada em balança de secagem acoplada a lâmpada de infravermelho (Marte, Modelo ID 50). Os ésteres de etila foram monitorados por cromatografia de fase gasosa (Varian 3800) (Urioste et al., 2008). Os valores da viscosidade absoluta dos produtos purificados foram medidos a $40^{\circ} \mathrm{C}$ em viscosímetro (Brookfield, Modelo LVDVII) empregando o cone CP 42.

\section{RESULTADOS E DISCUSSÃO}

As células imobilizadas sem tratamento (controle) apresentaram atividade hidrolítica média de $65,7 \mathrm{U} / \mathrm{g}$. O tratamento com GA não afetou negativamente a atividade catalítica do biocatalisador sendo obtido valor similar da ordem de 63,2 U/g. No entanto, o tratamento com Aliquat ${ }^{\circledR} 336$ reduziu o valor médio de atividade para 39,2 U/g, indicando uma acentuada desnaturação da lipase intracelular pela ação desse agente hidrofóbico. Esse comportamento não foi observado na imobilização de lipase extracelular, como reportado por Souza et al., 2012.

O comportamento dinâmico da formação dos ésteres de etila nas etanólises do óleo de babaçu em fluxo contínuo, catalisado pelos biocatalisadores tratados e não tratado (controle) nas mesmas condições operacionais mostrado na Figura 2 (a-c) indica diferentes desempenhos em função do 
biocatalisador utilizado.
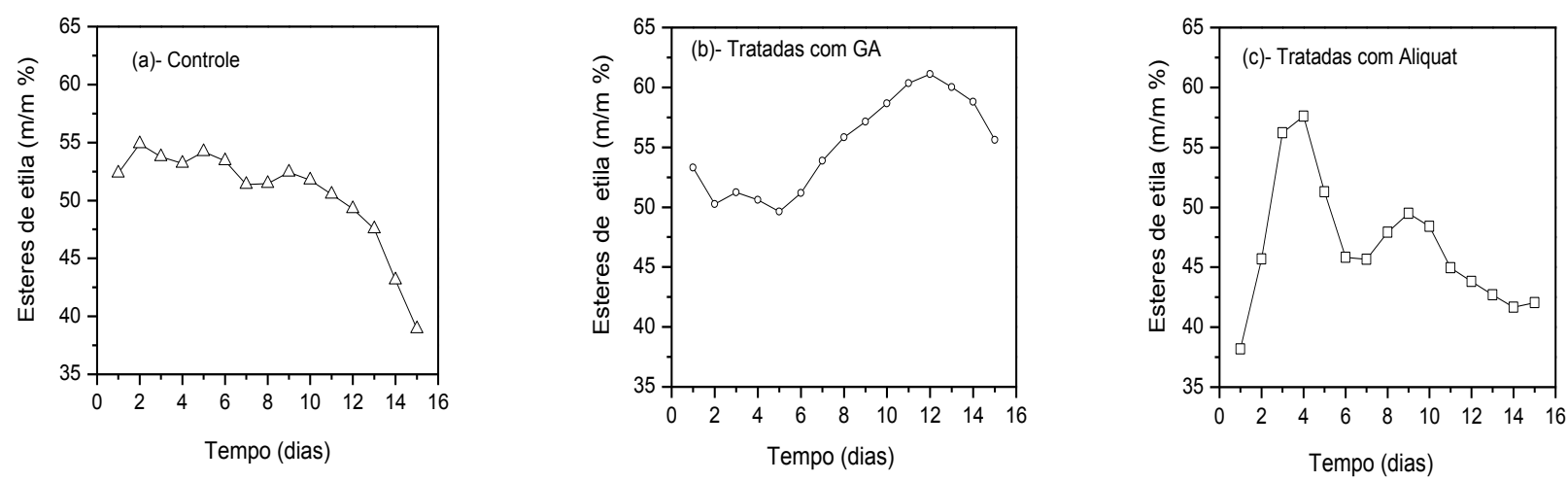

Figura 2 - Concentração total dos ésteres etílicos formados na etanólise do óleo de babaçu catalisado por células de $M$. circinelloides 4182 imobilizadas (a) sem tratamento - reação controle, (b) tratadas com GA e (c) tratadas com Aliquat 336

No sistema controle (Figura 2a) empregando células imobilizadas não tratadas, apesar de ter sido constatado uma estabilidade inicial do reator, a atividade de biocatalisador foi gradativamente reduzida ao longo do tempo resultando num decréscimo da ordem de $40 \%$ na concentração de ésteres formados. A concentração média de ésteres foi da ordem de 50,5 $44,4 \% \mathrm{~m} / \mathrm{m}$, correspondendo a rendimento de transesterificação de $67,8 \%$ e produto com viscosidade de 9,1 cSt. O emprego das células imobilizadas tratadas com GA (Figura 2b) gerou uma oscilação inicial não diretamente correlacionada com atividade do biocatalisador, seguida da formação crescente dos ésteres de etila. $\mathrm{O}$ valor máximo alcançado foi de $61,4 \% \mathrm{~m} / \mathrm{m}$, correspondendo a $75,5 \%$ de rendimento e produto com viscosidade de 8,4 cSt. Por outro lado, a utilização das células tratadas com Aliquat@ 336 provocou acentuada oscilação na concentração de ésteres formados (Figura 2c) ao longo de todo o período de operação do reator. A concentração de ésteres de etila variou entre 35,2 a 63,8\% (rendimentos de 43,3 a 78,5\%), com valores de viscosidade entre 13,5 e $8,7 \mathrm{cSt}$, respectivamente.

A partir dos resultados mostrados na Figura 2(a-c) foram determinadas as constantes de desativação $\left(k_{d}\right)$ e o tempo de meia-vida dos biocatalisadores $\left(\mathrm{t}_{1 / 2}\right)$ pelo ajuste dos dados experimentais ao modelo de desativação de primeira ordem. Os resultados obtidos são listados na Tabela 1. Dentre os sistemas testados, o tratamento das células imobilizadas com GA demonstrou ser o mais eficiente promovendo uma elevada estabilidade da atividade catalítica do biocatalisador, revelando um tempo de meia-vida de 42,8 dias, cerca de 1,65 vezes superior em relação ao biocatalisador controle. 
Tabela 1 -Estabilidade operacional das células de $M$. circinelloides imobilizadas na etanólise do óleo de babaçu operando em fluxo contínuo

\begin{tabular}{|l|c|c|}
\hline \multicolumn{1}{|c|}{ Biocatalisador } & $\mathbf{k}_{\mathbf{d}}\left(\mathbf{d i a}^{-\mathbf{1}}\right) \mathbf{x} \mathbf{x 1 0}^{\mathbf{3}}$ & $\mathbf{t}_{\mathbf{1} / \mathbf{2}}(\mathbf{d i a s})$ \\
\hline Controle & 26,7 & 25,9 \\
\hline GA 0,1\% & 16,2 & 42,8 \\
\hline Aliquat $0,1 \%$ & 33,8 & 20,5 \\
\hline
\end{tabular}

\section{CONCLUSÕES}

Os resultados obtidos sugerem a viabilidade técnica de aplicação de células integras de $M$. circinelloides imobilizadas em poliuretano para mediar a síntese enzimática de biodiesel em fluxo continuo, em função de sua satisfatória estabilidade operacional quando tratadas com glutaraldeído. Esses resultados se comparam favoravelmente com os dados descritos na literatura. $\mathrm{O}$ estudo das variáveis que interferem no processo em fluxo contínuo está em fase de desenvolvimento visando alcançar rendimentos similares aos obtidos em regime de batelada.

\section{AGRADECIMENTOS}

Os autores agradecem a FAPEMIG e ao CNPq pelo suporte financeiro.

\section{REFERENCIAS}

ABBASZAADEH, A., GHOBADIAN, B., OMIDKHAH, M. R., NAJAFI, G. Current biodiesel production technologies: A comparative review. Energy Convers. Manage., 138-148, 2012.

ANDRADE, G. S. S.; FREITAS, L.; OLIVEIRA, P. C.; DE CASTRO, H. F. Screening, immobilization and utilization of whole cell biocatalysts to mediate the ethanolysis of babassu oil $J$. Mol. Catal. B: Enzym., v. 84, p. 183-188, 2012.

FUKUDA, H.; KONDO, A.; TAMALAMPUDI, S. Bioenergy: Sustainable fuels from biomass by yeast and fungal whole-cell biocatalysts. Biochem. Eng. J., v. 44, p. 2-12, 2009.

ROBLES-MEDINA, A.; GONZÁLEZ-MORENO, P.A.; ESTEBAN-CERDÁN, L.; MOLINAGRIMA, E. Biocatalysis: Towards ever greener biodiesel production. Biotechnol. Adv., v. 27, p. 398408, 2009.

SOUZA, R. L.; RESENDE, W. C. S.; BARÃO, C. E.; ZANIN, G. M.; DE CASTRO, H. F.; SANTOS, O. A A., et al. Influence of the use of Aliquat 336 in the immobilization procedure in solgel of lipase from Bacillus sp. ITP-001. J. Mol. Catal B: Enzym., v. 84, p. 152-159, 2012.

URioste, D.; CAStro, M. B. A.; BiAgGiO, F. C.; DE CASTRO, H. F. Síntese de padrões cromatográficos e estabelecimento de método para dosagem da composição de ésteres de ácidos graxos presentes no biodiesel a partir do óleo de babaçu. Quim. Nova, v. 31, p. 407-412, 2008. 